\title{
Influência do Grão de Sorgo como Fonte de Amido em Ovinos Alimentados com Feno. Parâmetros Plasmáticos
}

\author{
Jorge López ${ }^{1}$, Waldyr Stumpf Junior ${ }^{2}$
}

\begin{abstract}
RESUMO - O objetivo deste trabalho experimental foi verificar a influência de diferentes níveis de grão de sorgo, como fonte de amido, nos parâmetros plasmáticos em ovinos alimentados com feno de capim-elefante (Pennisetum purpureum Schum). O sorgo foi utilizado em quatro níveis na dieta: $0,15,30$ e $45 \%$. Foram usados 12 ovinos machos castrados distribuídos em quatro tratamentos com três repetições. Foram coletadas seis amostras de sangue por animal logo antes da refeição da manhã (hora zero) e 1, 2, 3, 4, 6 e 8 horas após. O delineamento experimental foi o completamente casualizado. A $1^{\text {a }}$ hora após a refeição apresentou a maior concentração plasmática de uréia $(53,3 \mathrm{mg} / 100 \mathrm{~mL})$ e foi superior à $6^{\mathrm{a}}$ e $8^{\mathrm{a}}$ hora $(49,5$ e 49,3 mg/100 mL). A maior concentração de uréia no plasma coincidiu com a maior concentração de amônia no líquido ruminal. O tratamento com $30 \%$ de sorgo na dieta apresentou concentração plasmática de glicose de $81,0 \mathrm{mg} / 100 \mathrm{~mL}$ e foi superior ao tratamento testemunha $(60,4 \mathrm{mg} / 100 \mathrm{~mL})$. A concentração de insulina variou entre tratamentos para cada hora de coleta após a refeição, de acordo com os níveis de sorgo na dieta. O tratamento com $45 \%$ de sorgo apresentou a maior concentração do hormônio no plasma. Observou-se para todos os tratamentos um pico de produção do hormônio na $4^{\mathrm{a}}$ hora após a refeição.
\end{abstract}

Palavras-chave: amido, feno de gramínea, glicose, insulina, ovinos, uréia

\section{Influence of Sorghum Grain as a Source of Starch in Sheep Fed Hay. Plasma Parameters}

\begin{abstract}
The objective of this experimental work was to evaluate the influence of different levels of sorghum grain, as a source of starch, on the plasma parameters of sheep fed elephant grass hay (Pennisetum purpureum Schum). Sorghum grain was included in the diet at four levels: 0, 15, 30 e 45\%. Twelve castrated male sheep were assigned to four treatments with three replicates. Six samples of blood per animal were collected just before the morning feeding (zero hour) and after 1, 2, 3, 4, 6 and 8 hours. A completely randomized design was used. The first hour after feeding showed the highest plasma concentration of urea $(53.3 \mathrm{mg} / 100 \mathrm{~mL})$ and was higher than the six and eight-hour samples $(49.5$ and $49.3 \mathrm{mg} / 100 \mathrm{~mL})$. The higher concentration of urea in the plasma coincided with the highest concentration of ammonia in the ruminal liquor. Treatment including $30 \%$ sorghum in the diet showed a glucose plasmatic concentration of $81,0 \mathrm{mg} / 100 \mathrm{~mL}$ and was superior to the control treatment $(60.4 \mathrm{mg} / 100 \mathrm{~mL})$. Insulin concentration varied among treatments for each hour of collection after feeding according to the levels of sorghum in the diet. The treatment that included $45 \%$ sorghum grain showed the highest concentration of this hormone in the plasma. It was observed a peak of the insulin production at the four-hour after feeding.
\end{abstract}

Key Words: glucose, grass hay, insulin, sheep, starch, urea

\section{Introdução}

Os carboidratos são importantes na nutrição dos ruminantes. Estes animais foram preparados pela natureza para consumirem alimentos fibrosos a partir dos quais recebem energia, proteína, minerais e vitaminas para atender as suas exigências nutricionais. Esta constatação feita ao longo dos anos foi a determinante que orientou os pesquisadores a realizarem trabalhos de pesquisa envolvendo os alimentos fibrosos, os ruminantes e os microrganismos do rúmen.

Todavia, a necessidade de aumentar a produção de alimentos de origem animal, para uma população humana sempre em crescimento, determinou melhora na alimentação dos ruminantes por meio da utilização de pastagens melhoradas e na suplementação com concentrados.

Por estas razões, há mais de 40 anos, tem-se aumentado continuamente o número de trabalhos de pesquisa visando ao aumento da produtividade dos ruminantes com o uso de concentrados, com o objetivo de não apenas melhorar a qualidade da proteína fornecida, mas também o fornecimento de energia, de maneira mais concentrada. Assim, a pesquisa, sem abandonar o estudo das forrageiras e sua inter-relação com os ruminantes, passou a estu-

\footnotetext{
${ }_{1}^{1}$ Professor do Departamento de Zootecnia - UFRGS. Porto Alegre, RS. Bolsista do CNPq. E.mail: depzoo@vortex.ufrgs.br
}

2 Pesquisador da EMBRAPA Clima Temperado. Pelotas, RS. E-mail: stumpf@cpact.embrapa.br 
dar os carboidratos não-estruturais, como amido, açúcares solúveis, pectina e frutosanas (VAN SOEST, 1982), com maior ênfase no primeiro.

Algumas raízes e tubérculos (mandioca, batata, araruta, tupinambor) e os grãos de cereais são as fontes mais importantes de amido, com teores acima de 60\% (POORE et al., 1993). O sorgo apresenta teor médio de $72 \%$ (NOCEK e TAMINGA, 1991), com variação em função do cultivar, do ano e das condições climáticas.

No ruminante, o amido passa primeiro por fermentação microbiana no rúmen, com conseqüente produção de células microbianas e ácidos graxos voláteis (AGV), e o que não é transformado sofre, posteriormente, digestão enzimática no intestino delgado com liberação de glicose (WALDO, 1973). Segundo ØRSKOV (1986), o amido pode também ser fermentado no intestino grosso com produtos finais semelhantes aos da fermentação ruminal. Segundo WALDO (1973), o amido do sorgo é, provavelmente, em relação aos alimentos comuns, o mais resistente à fermentação ruminal. De acordo com OWENS et al. (1986), do amido do sorgo digerido em todo o trato gastrintestinal em bovinos, uma média de $80 \%$ foi digerida no trato pós-ruminal. A baixa digestão no rúmen é compensada pela alta digestibilidade em todo o trato gastrintestinal. Do amido que entra no intestino, somente $65 \%$ são digeridos, sendo que a média do desaparecimento deste ocorre no intestino delgado. Segundo esses autores, o amido digerido no intestino delgado apresentou aporte energético $42 \%$ superior ao do amido fermentado no rúmen. Teoricamente, é desejável que o amido escape da fermentação ruminal, evitando-se as perdas pela fermentação (ØRSKOV, 1986).

Duas fontes primárias de carboidrases pós-rúmen são o pâncreas e a mucosa intestinal. A hidrólise intestinal do amido com liberação de glicose requer enzimas capazes da clivagem das ligações glicosídicas $\alpha$ 1-4 e $\alpha$ 1-6 (amilase e amilopectina). A amilase pancreática hidrolisa a amilose e a maltotriose à maltose. A atividade da maltase no intestino delgado libera glicose (COOMBE e SIDDONS, 1973). A hidrólise da amilopectina é completada no intestino delgado pela isomaltase, uma vez que a amilase pancreática não possui atividade glicosídica $\alpha$ 1-6 (SIDDONS et al., 1968).

A importância do metabolismo da glicose para espécies ruminantes tem sido reconhecida há vários anos. Mais recentemente, trabalhos de pesquisa têm enfocado uma descrição quantitativa do metabolismo da glicose em tecidos de ruminantes e o controle do metabolismo dos carboidratos por meio das condições hormonais do animal (WEEKES, 1991).

De acordo com $\varnothing$ RSKOV (1986), o fígado de animais ruminantes, apesar de apresentar grande capacidade de produzir glicose por intermédio de outros intermediários, sendo que o mais importante é o ácido propiônico, não é um eficiente utilizador de glicose exógena. Assim, mesmo pequeno suprimento de glicose exógena estimula rápida produção de insulina. Os ruminantes dependem da gliconeogênese para manter concentrações plasmáticas de glicose (ETHERTON, 1982).

A insulina é o principal hormônio controlador da utilização da glicose pelos tecidos extra-hepáticos em ruminantes, como em outras espécies, apresentando ainda ação muito mais ampla, com influência também no metabolismo da proteína e dos lipídeos (WEEKES, 1991).

A ação primária da insulina no metabolismo da glicose ocorre mediante o estímulo de seu transporte, realizado pela aceleração na translocação das unidades transportadoras de glicose para a membrana plasmática. A insulina estimula a distribuição da glicose intracelular, por meio da ativação da glicogênio-sintetase e da inibição da glicogenólise, juntamente com a ativação da glicólise e da lipogênese e o uso da glicose como combustível oxidativo.

Vários fatores provavelmente determinam as concentrações de insulina - resposta à alimentação, sinais nervosos, hormônios gastrintestinais, aminoácidos e ácidos graxos voláteis, particularmente o propiônico. Segundo BERGMAN et al. (1970), as concentrações de insulina foram mais altas, quando a produção de glicose foi maior.

Estudando a relação uréia x energia, KENNEDY (1980) observou que o aumento na transferência de uréia do plasma para o rúmen em bovinos recebendo sacarose na dieta representou um adicional de $0,4 \%$ na passagem de nitrogênio microbiano para o abomaso, mostrando que a incorporação de amônia em proteína microbiana foi mais eficiente em novilhos recebendo sacarose, associado a declínio na concentração de amônia e, conseqüentemente, na taxa de absorção de amônia no rúmen. Segundo o autor, a proporção de entrada de uréia que foi degradada no trato gastrintestinal foi determinada pela dieta. As concentrações de uréia no plasma e amônia no rúmen afetaram a transferência de uréia para o rúmen em bovinos.

Thorton et al. (1970), citados por KENNEDY e 
Rev. bras. zootec.

MILLIGAN (1980), observaram que a provisão de uma fonte fermentável de energia para o trato digestivo pós-ruminal aumentou a excreção fecal de nitrogênio provavelmente pelo estímulo da síntese microbiana com transferência de uréia do plasma para o ceco e o cólon.

\section{Material e Métodos}

O trabalho experimental foi conduzido no Laboratório de Ensino Zootécnico (LEZO) do Departamento de Zootecnia da Faculdade de Agronomia da UFRGS, no Departamento de Bioquímica e no Departamento de Fisiologia do Instituto de Biociências da UFRGS.

O volumoso usado no experimento foi o feno de capim-elefante (Pennisetum purpureum, Schum) colhido quando as plantas tinham altura média em torno de 1,50 m e rebrota de 60 dias, ficando expostas ao sol por um período de três dias, sendo viradas duas vezes ao dia. O material seco foi prensado e acondicionado em fardos. O grão de sorgo, usado como fonte de amido, foi produzido na EMBRAPA Clima Temperado, peneirado antes do uso para eliminar impurezas e, posteriormente, moído.

Foram utilizados doze ovinos machos castrados, com idade em torno de 15 meses e peso vivo médio de $26,8 \mathrm{~kg}$. Os animais foram fistulados no rúmen, para colocação de cânulas permanentes de PVC rígido, e tosados, além de receberem anti-helmíntico após exame parasitológico das fezes. Durante 15 dias foram mantidos em baias coletivas, onde receberam à vontade minerais, água e uma mistura de fenos picados, composta de alfafa e capim-elefante. No final desse período, os animais foram pesados de manhã e colocados nas gaiolas metabólicas de forma aleatória.

Foram adicionados níveis crescentes de grão de sorgo moído $(0,15,30$ e $45 \%)$ a uma dieta basal de feno de capim-elefante fornecido à vontade durante todo o período experimental. Para nivelar os teores de proteína bruta (PB), foi adicionado farelo de soja a todas as dietas.

Foram sorteados e testados quatro tratamentos com a seguinte composição: $\mathrm{T}_{0}$ (testemunha) $=$ feno de capim elefante $(\mathrm{FCE})+$ farelo de soja $(\mathrm{FS}) ; \mathrm{T}_{1}=$ $\mathrm{FCE}+\mathrm{FS}+15 \%$ de grão de sorgo (GS); $\mathrm{T}_{2}=\mathrm{FCE}+$ $\mathrm{FS}+30 \% \mathrm{GS} ; \mathrm{e} \mathrm{T}_{3}=\mathrm{FCE}+\mathrm{FS}+45 \% \mathrm{GS}$.

A composição média dos ingredientes das dietas e sua composição químico-bromatológica podem ser observadas nas Tabelas 1, 2 e 3.

Em função do consumo de feno, os animais receberam o suplemento concentrado, a fim de atingir os níveis
1185

Tabela 1 - Composição química dos ingredientes utilizados nas dietas, expressa como porcentagem da matéria seca

Table 1 - Chemical composition of the ingredients used in the diets as a percentage of dry matter

\begin{tabular}{lccc}
\hline Nutriente & \multicolumn{3}{c}{$\begin{array}{c}\text { Ingrediente } \\
\text { Ingredient }\end{array}$} \\
\cline { 2 - 4 } & $\begin{array}{c}\text { Feno } \\
\text { Hay }\end{array}$ & $\begin{array}{c}\text { Farelo de soja } \\
\text { Soybean meal }\end{array}$ & $\begin{array}{c}\text { Sorgo } \\
\text { Sorghum }\end{array}$ \\
\hline $\begin{array}{l}\text { Matéria seca (\%) } \\
\text { Dry matter }\end{array}$ & 90,17 & 88,66 & 86,96 \\
$\begin{array}{l}\text { Matéria orgânica (\%) } \\
\text { Organic matter }\end{array}$ & 90,04 & 93,51 & 98,71 \\
$\begin{array}{l}\text { Proteína bruta (\%) } \\
\text { Crude protein }\end{array}$ & 5,12 & 55,25 & 10,12 \\
$\begin{array}{l}\text { FDN(\%) } \\
\text { NDF } \\
\text { Amido (\%) }\end{array}$ & 76,05 & 12,82 & 16,42 \\
Starch & 3,91 & 4,44 & 61,21 \\
\hline
\end{tabular}

Tabela 2 - Composição das dietas, expressa como porcentagem de matéria seca

Table 2 - Composition of the diets as a percentage of dry matter

\begin{tabular}{lcccc}
\hline Ingrediente & \multicolumn{4}{c}{$\begin{array}{c}\text { Tratamento } \\
\text { Treatment }\end{array}$} \\
\cline { 2 - 5 } & $\mathrm{T}_{0}$ & $\mathrm{~T}_{1}$ & $\mathrm{~T}_{2}$ & $\mathrm{~T}_{3}$ \\
& $(0 \%)$ & $(15 \%)$ & $(30 \%)$ & $(45 \%)$ \\
\hline $\begin{array}{l}\text { Feno (\%) } \\
\text { Hay }\end{array}$ & 82,93 & 68,98 & 53,01 & 38,45 \\
$\begin{array}{l}\text { Farelo de soja (\%) } \\
\text { Soybean meal }\end{array}$ & 17,07 & 15,15 & 14,10 & 12,62 \\
$\begin{array}{l}\text { Sorgo (\%) } \\
\text { Sorghum }\end{array}$ & - & 15,87 & 32,89 & 48,93 \\
\hline
\end{tabular}

Tabela 3 - Composição química das dietas, expressa como porcentagem da matéria seca

Table 3 - Chemical composition of the diets as a percentage of dry matter

\begin{tabular}{|c|c|c|c|c|}
\hline \multirow[t]{2}{*}{$\begin{array}{l}\text { Nutriente } \\
\text { Nutrient }\end{array}$} & \multicolumn{4}{|c|}{$\begin{array}{c}\text { Tratamento } \\
\text { Treatment }\end{array}$} \\
\hline & $\begin{array}{c}\mathrm{T}_{0} \\
(0 \%)\end{array}$ & $\begin{array}{c}\mathrm{T}_{1} \\
(15 \%)\end{array}$ & $\begin{array}{c}\mathrm{T}_{2} \\
(30 \%)\end{array}$ & $\begin{array}{r}\mathrm{T}_{3} \\
(45 \%)\end{array}$ \\
\hline $\begin{array}{l}\text { Matéria seca (\%) } \\
\text { Dry matter }\end{array}$ & 89,91 & 89,07 & 88,90 & $\overline{88,41}$ \\
\hline Matéria orgânica (\%) & 90,62 & 91,90 & 93,32 & 94,46 \\
\hline $\begin{array}{l}\text { Proteína bruta (\%) } \\
\text { Crude protein }\end{array}$ & 13,55 & 13,45 & 13,78 & 13,87 \\
\hline $\begin{array}{l}\text { FDN }(\%) \\
N D F\end{array}$ & 65,41 & 57,28 & 47,98 & 39,35 \\
\hline $\begin{array}{l}\text { Amido }(\%) \\
\text { Starch }\end{array}$ & 4,00 & 12,86 & 22,41 & 31,55 \\
\hline
\end{tabular}


de sorgo e nitrogênio desejados. A alimentação foi fornecida às $8 \mathrm{e} 16 \mathrm{~h}$ e o concentrado foi fornecido primeiro e separado do volumoso, a fim de atingir o consumo desejado de concentrado e quantificar o consumo da dieta basal e do concentrado. Água e mistura mineral comercial foram fornecidas à vontade.

A concentração de componentes plasmáticos foi estudada em amostras de sangue coletadas, no último dia do período de coleta total, para a determinação de consumo e digestibilidade. Foi coletado líquido de rúmen e imediatamente coletado o sangue do mesmo animal, por meio de punção da veia jugular, utilizando-se "vacutainers" heparinizados. Foram coletadas seis amostras por animal, ou seja, logo antes da refeição da manhã (hora zero) e 1, 2, 3, 4, 6 e 8 horas após a mesma. O material foi imediatamente colocado em refrigerador.

As amostras de sangue foram centrifugadas a $3000 \mathrm{rpm}$ por 20 minutos, retirando-se duas alíquotas de $2 \mathrm{~mL}$ do sobrenadante.

A concentração plasmática de glicose foi determinada pelo método enzimático-colorimétrico da glicose-oxidase, com a utilização de um kit comercial (Sigma C.C.). A uréia plasmática foi determinada pelo método químico colorimétrico, empregando-se um kit comercial (Doles). A determinação de insulina no plasma foi realizada por meio de radioimunoensaio de anticorpo, utilizando um kit comercial (Diagnostic Product Corporation). O delineamento experimental utilizado foi inteiramente casualizado. A análise dos dados foi realizada por intermédio de um modelo em parcelas subdivididas, nas quais os animais constituíram a parcela principal e os tempos, a subparcela, uma vez que o tempo de coleta do material foi considerado um fator experimental (HALL, 1973). As médias foram comparadas pelo teste de Tukey $(\mathrm{P}<0,05)$. Realizaram-se também regressões lineares e quadráticas. Para análise dos dados, foi utilizado o programa GIVENS (FRIES, 1987).

\section{Resultados e Discussão}

A transferência de uréia do sangue para o trato digestivo de ruminantes é, potencialmente, importante fonte de nitrogênio para o desenvolvimento da população microbiana no rúmen-retículo e intestino grosso.

No presente trabalho não foi observada diferença nos níveis de uréia no plasma entre tratamentos (Tabela 4), porém foi observada diferença significativa $(\mathrm{P}<0,05)$ na concentração de uréia entre horas de coleta após a refeição. A Tabela 5 mostra que a $1^{\text {a }}$ hora após a refeição apresentou a maior concentração de uréia $(53,3 \mathrm{mg} / 100 \mathrm{~mL})$ e foi, em média, $7 \%$ superior $(\mathrm{P}<0,05)$ à $6^{\mathrm{a}} \mathrm{e} 8^{\mathrm{a}}$ horas $(49,5 \mathrm{e} 49,3 \mathrm{mg} / 100 \mathrm{~mL})$. A concentração na $1^{\mathrm{a}}$ hora foi semelhante às concentrações das horas $0,2^{\mathrm{a}}$ e $4^{\mathrm{a}}$, as quais não diferiram entre si. A maior concentração de uréia no plasma na $1^{\text {a }}$ hora após a refeição coincidiu com a maior concentração de amônia no líquido ruminal (STUMPF JR., 1992).

Segundo KENNEDY e MILLIGAN (1980), a transferência de uréia para o rúmen correlacionou-se negativamente com a concentração de amônia ruminal e positivamente com a concentração de uréia no plasma e com a matéria orgânica aparentemente digerida no rúmen. A transferência de uréia foi afetada pelo consumo de nitrogênio e energia metabolizável.

Tabela 4 - Valores médios das concentrações plasmáticas de uréia, glicose e insulina Table 4 - Average values for the plasma concentration of urea, glucose and insulin

\begin{tabular}{|c|c|c|c|c|c|}
\hline \multirow[t]{2}{*}{$\begin{array}{l}\text { Metabólito } \\
\text { Metabolite }\end{array}$} & \multicolumn{4}{|c|}{$\begin{array}{c}\text { Tratamento } \\
\text { Treatment }\end{array}$} & \multirow[t]{2}{*}{$\begin{array}{l}\text { Erro-padrão da média } \\
\text { Standard error mean }\end{array}$} \\
\hline & $\begin{array}{c}\mathrm{T}_{0} \\
(0 \%)\end{array}$ & $\begin{array}{c}\mathrm{T}_{1} \\
(15 \%)\end{array}$ & $\begin{array}{c}\mathrm{T}_{2} \\
(30 \%)\end{array}$ & $\begin{array}{c}\mathrm{T}_{3} \\
(45 \%)\end{array}$ & \\
\hline $\begin{array}{l}\text { Uréia }(\mathrm{mg} / 100 \mathrm{~mL}) \\
\text { Urea }\end{array}$ & $56,0^{\mathrm{ns}}$ & $45,1^{\mathrm{ns}}$ & $47,7^{\text {ns }}$ & $55,5^{\mathrm{ns}}$ & 6,6 \\
\hline $\begin{array}{l}\text { Glicose }(\mathrm{mg} / 100 \mathrm{~mL}) \\
\text { Glucose }\end{array}$ & $60,4^{c}$ & $72,3^{a b c}$ & $81,0^{\mathrm{a}}$ & $80,5^{\mathrm{ab}}$ & 13,07 \\
\hline $\begin{array}{l}\text { Insulina }(\mu \mathrm{U} / \mathrm{mL}) \\
\text { Insulin }\end{array}$ & $19,4^{\mathrm{ns}}$ & $26,5^{\mathrm{ns}}$ & $38,7^{\mathrm{ns}}$ & $44,6^{\mathrm{ns}}$ & 12,0 \\
\hline
\end{tabular}

Médias, na linha, seguidas de letras diferentes diferem pelo teste Tukey $(P<0,05)$.

Means, within a row, followed by different letters differ by Tukey test $(P<.05)$.

ns = Não-significativo.

$n s=$ Non significant . 
Tabela 5 - Valores médios das concentrações plasmáticas de uréia $(\mathrm{mg} / 100 \mathrm{~mL})$ para horas de coleta após alimentação

Table 5 - Average values of plasma urea concentration $(\mathrm{mg} / 100 \mathrm{~mL})$ for sampling time after feeding

\begin{tabular}{lcccccc}
\hline $\begin{array}{l}\text { Tratamento } \\
\text { Treatment }\end{array}$ & \multicolumn{7}{c}{$\begin{array}{c}\text { Tempo após alimentação }(\mathrm{h}) \\
\text { Time after feeding }(h)\end{array}$} \\
\cline { 2 - 7 } & 0 & 1 & 2 & 4 & 6 & 8 \\
\hline $\mathrm{T}_{0}(0 \%)$ & 56,0 & 56,7 & 55,2 & 57,6 & 56,1 & 54,5 \\
$\mathrm{~T}_{1}(15 \%)$ & 44,7 & 47,0 & 47,9 & 44,8 & 43,5 & 42,7 \\
$\mathrm{~T}_{2}(30 \%)$ & 47,8 & 50,7 & 48,1 & 48,1 & 47,3 & 44,6 \\
$\mathrm{~T}_{3}(45 \%)$ & 58,9 & 59,0 & 56,1 & 52,6 & 51,0 & 55,4 \\
Média & $51,9^{\text {ab }}$ & $53,4^{\mathrm{a}}$ & $51,8^{\mathrm{ab}}$ & $50,8^{\mathrm{ab}}$ & $49,5^{\mathrm{b}}$ & $49,3^{\mathrm{b}}$ \\
Mean & & & & & & \\
\hline
\end{tabular}

$a, b=$ Médias, na linha, seguidas de letras diferentes diferem pelo teste Tukey $(P<0,05)$.

$a, b=$ Means, within a row, followed by different letters differ by Tukey test $(P<.05)$.

Segundo Lewis (1975), citado por MULHOLLAND et al. (1976), o principal fator controlador dos níveis de uréia no plasma é a formação de amônia no rúmen, e o nível de uréia no sangue parece refletir as modificações na produção de amônia ruminal. Os dados do presente trabalho mostram que o aumento no consumo de amido não alterou as concentrações plasmáticas de uréia entre tratamentos. Isto pode ter sido devido às altas concentrações de amônia no rúmen em todos os tratamentos, decorrente de lenta taxa de degradação do amido do sorgo.

As altas concentrações plasmáticas de uréia, devidas aos tratamentos, foram semelhantes às observadas por MULHOLLAND et al. (1976) que, trabalhando com ovinos alimentados com níveis crescentes de amido na dieta ( 0 a $40 \%$ ), observaram níveis plasmáticos médios de uréia de $42 \mathrm{mg} / 100 \mathrm{~mL}$. Esses autores também não observaram diferença na concentração de uréia plasmática entre os tratamentos. Segundo HENNESSY et al. (1983), o aumento da produção e absorção de amônia do rúmen, proveniente de frações solúveis e degradáveis de proteína suplementar, seria responsável por parte do aumento da síntese de uréia a partir de amônia no fígado.

Ruminantes consumindo dietas ricas em volumosos e com baixo teor de amido dependem da síntese hepática de glicose para suprir suas exigências metabólicas. Os principais substratos para a síntese de glicose são os ácidos orgânicos da fermentação ruminal (principalmente ácido propiônico e ácido láctico), as cadeias de carbono de aminoácidos deaminados e o glicerol proveniente das gorduras (HUNTINGTON, 1994). Em dietas concentradas, ricas em amido, grandes quantidades de amido escapam da fermentação ruminal e passam para o intes- tino, no qual podem ser digeridas e utilizadas como fonte direta de glicose absorvida desde o trato digestivo (TOPPS et al., $1968 \mathrm{a}, \mathrm{b}$ ).

Neste trabalho foi observada diferença significativa $(\mathrm{P}<0,05)$ na concentração de glicose no plasma entre tratamentos (Tabela 4). O tratamento $\mathrm{T}_{2}(30 \%$ de sorgo) com concentração de $81,0 \mathrm{mg} / 100 \mathrm{~mL}$ foi superior em $34 \%$ ao tratamento testemunha, que apresentou concentração de 60,4 mg/100 mL. Houve semelhança $(\mathrm{P}>0,05)$ na concentração de glicose entre os tratamentos com 15, 30 e $45 \%$ de sorgo.

Conforme pode ser observado na Tabela 6 , houve aumento nas concentrações de glicose em $\mathrm{T}_{1}(15 \%)$, $\mathrm{T}_{2}(30 \%)$ e $\mathrm{T}_{3}$ (45\% de sorgo), que foi acompanhado por incremento nas proporções molares de ácido propiônico no rúmen e pelo aumento no consumo de amido digestível da dieta. Observando-se os dados de consumo de amido (Tabela 6) e considerando-se digestão ruminal média para o amido do grão de sorgo em torno de $65 \%$, de acordo com OWENS et al. (1986), e com dados de digestibilidade in situ da matéria seca do grão de sorgo observados por STUMPF JR. (1992), foi estimada a digestão de amido nos intestinos dos animais dos tratamentos $\mathrm{T}_{1}$, $\mathrm{T}_{2} \mathrm{e}_{3}$ de 30,1; 72,0; e 105,1 g/dia, respectivamente.

Não foi observada diferença nas concentrações de glicose entre os horários de coleta após a refeição (Tabela 1). Katz e Bergman (1969), citados por JUDSON e LENG (1973), relataram que a produção hepática de glicose em ovinos foi maior às $2 \mathrm{e} 4$ horas após a alimentação. Foi observada tendência de aumento $(\mathrm{P}=0,15)$ na proporção molar de ácido propiônico nos animais do tratamento $\mathrm{T}_{3}(45 \%$ de sorgo) entre a $1^{\mathrm{a}}$ e $6^{\mathrm{a}}$ hora, atingindo ponto máximo na $4^{\mathrm{a}}$ hora de coleta. Nos animais dos tratamentos $\mathrm{T}_{1} \mathrm{e}$ 


\begin{tabular}{|c|c|c|c|c|}
\hline \multirow{2}{*}{$\begin{array}{l}\text { Parâmetros } \\
\text { Parameters }\end{array}$} & \multicolumn{4}{|c|}{$\begin{array}{l}\text { Tratamento } \\
\text { Treatment }\end{array}$} \\
\hline & $\begin{array}{c}\mathrm{T}_{0} \\
(0 \%)\end{array}$ & $\begin{array}{c}\mathrm{T}_{1} \\
(15 \%)\end{array}$ & $\begin{array}{c}\mathrm{T}_{2} \\
(30 \%)\end{array}$ & $\begin{array}{c}\mathrm{T}_{3} \\
(45 \%)\end{array}$ \\
\hline Glicose no sangue $(\mathrm{mg} / 100 \mathrm{~mL})$ & 60,4 & 72,3 & 81,0 & 80,5 \\
\hline Glucose in the blood & & & & \\
\hline $\begin{array}{l}\text { Ácido acético (\%) } \\
\text { Acetic acid }\end{array}$ & 69,3 & 69,6 & 66,3 & 63,2 \\
\hline $\begin{array}{l}\text { Ácido propiônico }(\%) \\
\text { Propionic acid }\end{array}$ & 19,5 & 18,7 & 20,8 & 25,1 \\
\hline $\begin{array}{l}\text { Ácido butírico (\%) } \\
\text { Butiric acid }\end{array}$ & 11,2 & 11,7 & 12,9 & 11,7 \\
\hline $\begin{array}{l}\text { Acético/Propiônico } \\
\text { Acetic/Propionic }\end{array}$ & 3,6 & 3,7 & 3,2 & 2,5 \\
\hline $\begin{array}{l}\text { Consumo de amido (g/dia) } \\
\text { Starch intake (g/day) }\end{array}$ & 33,3 & 105,6 & 230,4 & 328,2 \\
\hline $\begin{array}{l}\text { Excreção de amido (g/dia) } \\
\text { Starch excretion (g/day) }\end{array}$ & 2,9 & 8,3 & 24,7 & 28,0 \\
\hline $\begin{array}{l}\text { Amido digerido no rúmen }(\mathrm{g} / \mathrm{dia}) \\
\text { Digested starch in the rumen }(\mathrm{g} / \text { day) }\end{array}$ & 19,7 & 63,3 & 133,8 & 195,2 \\
\hline $\begin{array}{l}\text { Amido digerido nos intestinos (g/dia) } \\
\text { Digested starch in the intestines (g/day) }\end{array}$ & 10,6 & 34,1 & 72,0 & 105,1 \\
\hline
\end{tabular}

$\mathrm{T}_{2}$ (15 e 30\% de sorgo), as maiores proporções aconteceram na $1^{\mathrm{a}}$ e $6^{\mathrm{a}}$ horas. Segundo $\varnothing \mathrm{RSKOV}$ et al. (1969), a porcentagem de amido na matéria seca do abomaso aumentou até atingir o máximo às 5 e 6 horas após a refeição e, após, diminuiu até valores mais baixos, justamente antes da próxima refeição.

De acordo com os dados obtidos neste experimento, é possível pressupor que o aumento nas concentrações de glicose tenha sido ocasionado por dois fatores principais: a alta porcentagem de ácido propiônico no rúmen e a hidrólise do amido no intestino delgado e absorção direta da glicose.

O metabolismo da glicose está intimamente associado com o metabolismo de aminoácidos e lipídeos, por meio da ação endócrina da insulina e do glucagon. A concentração sangüínea de glicose, uréia, aminoácidos, ácidos graxos não-esterificados, cetonas e ácidos graxos voláteis normalmente diminui, em resposta à alta concentração de insulina (BELL et al., 1987). O aumento da concentração de insulina no sangue é associada à diminuição da gliconeogênese hepática e aumento no uso da glicose pelos tecidos periféricos, com exceção da glândula mamária (SANO et al., 1992).

Não foi observada diferença na concentração de insulina no sangue entre os tratamentos (Tabela 4). Todavia, foi detectada diferença significativa entre as horas de coleta $(\mathrm{P}<0,01)$ e na interação tratamento $\mathrm{x}$ hora de coleta $(\mathrm{P}<0,01)$.

A significância na interação $\mathrm{x} \mathrm{h}$ mostrou diferença na concentração de insulina entre tratamentos para cada hora de coleta de sangue. Com exceção da $4^{\mathrm{a}}$ hora após o fornecimento da refeição da manhã, nos demais horários não houve diferença significativa entre as concentrações de insulina (Tabela 8).

$\mathrm{O}$ tratamento $\mathrm{T}_{3}(45 \%$ de sorgo $)$ apresentou na $4^{\mathrm{a}}$ hora a maior concentração $(170,3 \mu \mathrm{U} / \mathrm{mL})$, sendo superior $(\mathrm{P}<0,01)$ ao tratamento $\mathrm{T}_{2}(145,7 \mu \mathrm{U} / \mathrm{mL})$, o qual foi superior $(\mathrm{P}<0,01)$ ao $\mathrm{T}_{1}(15 \%$ de sorgo $)$, que apresentou concentração de $88,3 \mu \mathrm{U} / \mathrm{mL}$; o tratamento $\mathrm{T}_{1}$ foi superior $(\mathrm{P}<0,01)$ ao tratamento testemunha $\left(\mathrm{T}_{0}\right)$, que apresentou concentração de $29,7 \mu \mathrm{U} / \mathrm{mL}$ (Figura 1). Estes dados corroboram os resultados de SUTTON et al. (1988), que, trabalhando com duas refeições diárias, verificaram resposta evidente na concentração de insulina, com pico de produção de hormônio ocorrendo às 3 e 4 horas depois de cada refeição. Os autores observaram aumento nas concentrações de ácido propiônico e insulina, e não dos outros ácidos, que foram maiores nas dietas mais concentradas.

Pode-se observar que os animais dos tratamentos com as maiores concentrações de sorgo na dieta apresentaram os maiores picos de insulina na $4^{\text {a }}$ hora de 
Rev. bras. zootec.

Tabela 7 - Valores médios das concentrações plasmáticas de glicose $(\mathrm{mg} / 100 \mathrm{~mL})$ para horas de coleta após alimentação

Table 7 - Average values of plasma glucose concentration $(\mathrm{mg} / 100 \mathrm{~mL})$ for sampling time after feeding

\begin{tabular}{lccccccc}
\hline $\begin{array}{l}\text { Tratamento } \\
\text { Treatment }\end{array}$ & \multicolumn{5}{c}{$\begin{array}{c}\text { Tempo após alimentação }(\mathrm{h}) \\
\text { Time afterfeeding }(h)\end{array}$} & \multirow{2}{*}{$\begin{array}{c}\text { Média } \\
\text { Mean }\end{array}$} \\
\cline { 2 - 7 } & 0 & 1 & 2 & 4 & 6 & 8 & \\
\hline $\mathrm{T}_{0}(0 \%)$ & 60,5 & 53,8 & 62,5 & 63,9 & 63,8 & 57,9 & $60,4^{\mathrm{c}}$ \\
$\mathrm{T}_{1}(15 \%)$ & 72,5 & 71,8 & 73,6 & 70,7 & 71,8 & 73,7 & $72,3^{\mathrm{abc}}$ \\
$\mathrm{T}_{2}(30 \%)$ & 85,0 & 77,6 & 80,0 & 83,9 & 79,5 & 80,1 & $81,0^{\mathrm{a}}$ \\
$\mathrm{T}_{3}(45 \%)$ & 82,7 & 77,9 & 83,6 & 80,2 & 81,2 & 77,7 & $80,5^{\mathrm{ab}}$ \\
\hline
\end{tabular}

Médias, na coluna, seguidas de letras iguais não diferem pelo teste Tukey $(P<0,05)$.

Means, within a column, followed by the same letters do not differ by Tukey test $(P<.05)$.

Tabela 8 - Valores médios de concentração plasmática de insulina $(\mu \mathrm{U} / \mathrm{mL})$ para horas de coleta após alimentação

Table 8 - Average values of plasma insulin concentration $(\mu U / m L)$ for sampling time after feeding

\begin{tabular}{lcccccr}
\hline $\begin{array}{l}\text { Tratamento } \\
\text { Treatment }\end{array}$ & \multicolumn{5}{c}{$\begin{array}{c}\text { Tempo após alimentação }(\mathrm{h}) \\
\text { Time afterfeeding }(h)\end{array}$} \\
\cline { 2 - 7 } & 0 & 1 & 2 & 4 & 6 & 8 \\
\hline $\mathrm{T}_{0}(0 \%)$ & $17,2^{\mathrm{a}}$ & $14,6^{\mathrm{a}}$ & $20,2^{\mathrm{a}}$ & $29,7^{\mathrm{a}}$ & $20,4^{\mathrm{a}}$ & $14,5^{\mathrm{a}}$ \\
$\mathrm{T}_{1}(15 \%)$ & $16,7^{\mathrm{a}}$ & $11,1^{\mathrm{a}}$ & $16,5^{\mathrm{a}}$ & $88,3^{\mathrm{c}}$ & $17,3^{\mathrm{a}}$ & $9,1^{\mathrm{a}}$ \\
$\mathrm{T}_{2}(30 \%)$ & $13,3^{\mathrm{a}}$ & $17,7^{\mathrm{a}}$ & $16,5^{\mathrm{a}}$ & $145,7^{\mathrm{b}}$ & $23,3^{\mathrm{a}}$ & $15,4^{\mathrm{a}}$ \\
$\mathrm{T}_{3}(45 \%)$ & $13,4^{\mathrm{a}}$ & $28,3^{\mathrm{a}}$ & $18,7^{\mathrm{a}}$ & $170,3^{\mathrm{a}}$ & $16,9^{\mathrm{a}}$ & $19,8^{\mathrm{a}}$ \\
Média & $15,1^{\mathrm{b}}$ & $17,9^{\mathrm{b}}$ & $18,0^{\mathrm{b}}$ & $108,5^{\mathrm{a}}$ & $19,5^{\mathrm{b}}$ & $14,7^{\mathrm{b}}$ \\
Mean & & & & & &
\end{tabular}

Médias, na linha, seguidas de letras diferentes diferem pelo teste Tukey $(P<0,05)$

Médias, na coluna, seguidas de letras diferentes diferem pelo teste Tukey $(P<0,05)$.

Means, within a row, followed by different letters differ by Tukey test $(P<.05)$.

Means, within a column, followed by different letters differ by Tukey test $(P<.05)$.

coleta e, em função destes picos, tenderam a apresentar as maiores concentrações de insulina no sangue.

De acordo com a Figura 1, houve nos tratamentos $\mathrm{T}_{2}$ e $\mathrm{T}_{3}$ pequeno pico de insulina na $1^{\mathrm{a}}$ hora após a refeição, seguido por um segundo pico na $4^{\mathrm{a}}$ hora. Esta tendência de aumento na concentração de insulina provavelmente esteja associada tanto às maiores concentrações médias de glicose no plasma, como às maiores proporções molares de ácido propiônico no líquido ruminal apresentadas nos tratamentos com as maiores concentrações de amido na dieta. O tratamento testemunha ( $0 \%$ de sorgo) praticamente não apresentou pico na concentração de insulina ao longo do período observado.

As taxas temporais de secreção de insulina provavelmente afetam o metabolismo, favorecendo o anabolismo nos tecidos (SUTTON et al., 1988).

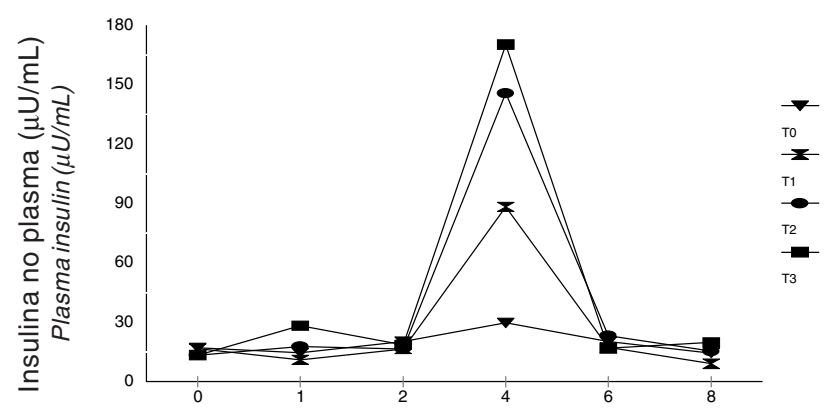

Tempo após alimentação (h)

Time after feeding $(h)$

Figura 1 - Variação na concentração de insulina no plasma $(\mu \mathrm{U} / \mathrm{mL})$ por tratamento e hora de coleta.

Figure 1 - Variation on insulin concentration in the plasma $(\mu U / m L)$ per treatment and hour of collection. 


\section{Conclusões}

A máxima concentração de uréia no sangue ocorreu às duas horas após a alimentação.

O amido do grão de sorgo contribuiu para melhorar os níveis plasmáticos de glicose e insulina, com as maiores taxas ocorrendo às 4 horas após a alimentação.

\section{Referências Bibliográficas}

BELL, A.W., BAUMAN, D.E., CURRIE, W.B. 1987. Regulation of nutrient partitioning and metabolism during pre-and postnatal growth. J. Anim. Sci., 65(1):186.

BERGMAN, E.N., KATZ, M.L., KAUFMAN, C.F. 1970. Quantitative aspects of hepatic and portal glucose metabolism and turnover in sheep. Am. J. Physiol., 219(3):785-793.

COOMBE, V.B., SIDDONS, R.C. 1973. Carbohydrate of the bovine small intestine. Br. J. Nutr., 30:269-276.

ETHERTON, T.D. 1982. The role of insulin-receptor interactions in regulation of nutrient utilization by skeletal muscle and adipose tissue: A review. J. Anim. Sci., 54(1):58-67.

FRIES, L.A. Givens - Um sistema de análises estatísticas de dados não balanceados por microcomputador. In: REUNIÃO ANUAL DA SOCIEDADE BRASILEIRA DE ZOOTECNIA, 24, 1987, Brasília. Anais...Brasília: SBZ, 1987. p.299.

HALL, W.B. 1975. Repeated measurements experiments. In: DEVELOPMENTS in field experiment design and analysis. Farnham Royal, CAB. p.33-42. (Bulletin, 50).

HENNESSY, D.W., WILLIAMSON, P.J., NOLAN, J.V. et al. 1983. The roles of energy or protein-rich supplements in the subtropics for young cattle consuming basal diets that are low in digestible energy and protein. J. Agric. Sci., 100(3):657-666.

HUNTINGTON, G.B. 1994. Ruminant starch utilization progress has been extensive. Feedstuffs, 66(23):16-18, 39-43.

JUDSON, G.J., LENG, R.A. 1973. Studies on the control of gluconeogenesis in sheep: effect of propionate, casein and butyrate infusions. Br. J. Nutr., 29:175-195.

KENNEDY, P.M. 1980. The effects of dietary sucrose and the concentrations of plasma urea, rumen ammonia on the degradation of urea in the gastrointestinal tract of cattle. $\mathrm{Br}$. $J$. Nutr., 43:125-140.

KENNEDY, P.M., MILLIGAN, L.P. 1980. The degradation and utilization of endogenous urea in the gastrointestinal tract of ruminants: A review. Can. J. Anim. Sci., 60(2):205-221.

MULHOLLAND, J.G., COOMBE, J.B., McMANUS, W.R. 1976. Effect of starch on the utilization by sheep of a straw diet supplemented with urea and minerals. Aust. J. Agric. Res., 27:139-153.

NOCEK, J.E., TAMINGA, S. 1991. Site of digestion in the gastrointestinal tract of dairy cows and its effects on milk yield and composition. J. Dairy Sci., 74(10):3598-3629. $\varnothing$ RSKOV, E.R. 1986. Starch digestion and utilization in ruminants. J. Anim. Sci., 63(5):1624-1633.

ØRSKOV, E.R., FRASER, C., KAY, R.N.B. 1969. Dietary factors influencing the digestion of starch in the rumen and small and large intestine of early weaned lambs. Br. J. Nutr., 23:217-226.

OWENS, F.N., ZINN, R.A., KIM, Y.K. 1986. Limits to starch digestion in the ruminants small intestine. J. Anim. Sci., 63:1634-1648.

POORE, M.H., MOORE, J.A., ECK, R.S. et al. 1993. Effect of fiber source and ruminal starch degradability on site and extent of digestion in dairy cows. J. Anim. Sci., 76(11):2244-2253.

SANO, H., MATSUNOBU, S., ABE, T. et al. 1992. Combined effects of diet and cold exposure on insulin responsiveness to glucose and tissue responsiveness to insulin in sheep. J. Anim. Sci., 70:3514-3520.

SIDDONS, R.C. 1968. Carbohydrate activities in the bovine digestive tract. Biochem. J., 108:839-842.

STUMPF JR., W. Influência do amido do sorgo e da mandioca sobre a digestibilidade, parâmetros ruminais e plasmáticos em ovinos alimentados comfeno: Porto Alegre, RS: UFRGS, 1992. 343p. Tese (Doutorado em Zootecnia) - Universidade Federal do Rio Grande do Sul, 1992.

SUTTON, J.D., HART, I.C., MORANT, S. et al. 1988. Feeding frequency for lactating cows: diurnal patterns of hormones and metabolites in peripheral blood in relation to milk-fat concentration. Br. J. Nutr., 60:265-274.

TOPPS, J.H, KAY, R.N.B, GOODALL, E.D. 1968a. Digestion of concentrate and of hay diets in the stomach and intestine of ruminants. Br. J. Nutr., 22:261-279.

TOPPS, J.H, KAY, R.N.B, GOODALL, E.D. 1968b. Digestion of concentrate and of hay diets in the stomach and intestine of ruminants. Br. J. Nutr., 22:281-290.

VAN SOEST, P.J. 1982. Nutricional ecology of the ruminant. Corvallis: O \& B Books. 374p.

WALDO, D.R. 1973. Extent and partition of cereal grain starch digestion in ruminants. J. Anim. Sci., 37(4):1062-1074.

WEEKES, T.E.C. Hormonal control of glucose metabolism. In: INTERNATIONAL SYMPOSIUM ON RUMINANT PHYSIOLOGY, 7, Sendai-Japão, 1989. Physiological aspects of digestion and metabolism in ruminants. San Diego, Academic Press. 1991. p.183-200.
Recebido em: 11/01/1998

Aceito em: 07/01/2000 